BMJ Open

Sport \&

Exercise

Medicine

\section{Systematic review of motor control and somatosensation assessment tests for the ankle}

To cite: Bertrand-Charette M, Dambreville C, Bouyer LJ, et al. Systematic review of motor control and somatosensation assessment tests for the ankle. BMJ Open Sport \& Exercise Medicine 2020;6:e000685. doi:10.1136/ bmjsem-2019-000685

- Additional material is published online only. To view please visit the journal online (http://dx.doi.org/10.1136/ bmjsem-2019-000685).

Accepted 19 May 2020

\section{Check for updates}

(c) Author(s) (or their employer(s)) 2020. Re-use permitted under CC BY. Published by BMJ.

${ }^{1}$ Department of Rehabilitation, Faculty of Medicine, Laval University, Quebec City, Quebec, Canada

${ }^{2}$ Center for Interdisciplinary Research in Rehabilitation and Social Integration, Quebec City, Quebec, Canada

Correspondence to Dr Jean-Sébastien Roy; Jean-Sebastien.Roy@fmed. ulaval.ca

\section{ABSTRACT}

Background/Aim Ankle sprains are frequent musculoskeletal injuries that can lead to sensorimotor deficits provoking long-term instability at the ankle joint. A broad variety of clinical tests currently exist to assess sensorimotor processing, and are commonly clinically referred to as proprioceptive tests. However, there is a discrepancy in the use of the term proprioception when looking at the main outcome of these tests. As identifying specific deficits is important for motor recovery, it is critical for clinicians to select the most appropriate tests.

Methods A systematic review of four databases was performed to provide an up-to-date review of the psychometric properties of available tests referred to as proprioceptive tests. Seventy-nine articles on eight ankle proprioceptive tests were included and critically appraised. Data on validity, reliability and responsiveness were extracted from the included articles and synthesised. The tests reviewed were then divided into two categories based on their main outcome: motor control or somatosensation.

Results Strong evidence showed that the Star Excursion Balance Test, a motor control test, is capable of differentiating between stable and unstable ankles. Moderate evidence suggests that somatosensation tests, such as Joint Position Sense, are also valid and reliable, but their responsiveness has yet to be evaluated.

Conclusions Together, these findings indicate that the Star Excursion Balance Test can be used in the clinic to assess motor control based on its excellent psychometric properties. However, as ankle stability control involves complex sensorimotor interactions, care has to be taken regarding the use of this test as a specific tool for proprioception assessment.

\section{INTRODUCTION}

Ankle sprain is one of the most common musculoskeletal injuries, ${ }^{1-6}$ with lateral ankle sprain being the most frequent. ${ }^{2}$ Following an ankle sprain, several midterm and longterm deficits can be observed such as loss of functional ability and subjective instability (described as the perception that the ankle is giving away). ${ }^{7-11}$ van Rijn et al reported that there is a large variation in the occurrence of subjective instability (up to 33\%), and

\section{Key messages}

Previous systematic reviews found that Star Excursion Balance Test (SEBT), Threshold for Perception of Passive Movement (TPPM) and Joint Position Sense (JPS) are valid tests that can discriminate between stable and unstable ankles.

- Our study added a new understanding regarding tests usually described as proprioceptive tests by giving recommendations specifically for motor control or somatosensation outcomes.

- Since there is a discrepancy in the literature regarding the use of the term proprioception, we categorised ankle tests into two groups depending on their main outcome: motor control or somatosensation.

- Contrary to previous studies, we compared eight of the most studied categories of clinical tests and concluded that SEBT is the most valid, reliable and responsive test regarding the participant's motor control, while JPS and TPPM are valid and reliable alternatives assessing somatosensation.

that while it decreases in the long term, it can take up to 3 years after the sprain before subjective instability is no longer perceived. ${ }^{8}$ Hertel $^{12}$ and Munn et at ${ }^{9}$ suggested that the persistence of sensorimotor deficits following ankle sprains could explain subjective ankle instability.

Instability can result from three types of deficits related to sensorimotor function: motor (eg, weakness), somatosensory (eg, injury to proprioceptors or cutaneous receptors) and/or processing of somatosensory information. Proprioception, a term commonly used in clinical rehabilitation to describe the somatosensory processing aspects of joint stability, is an integral part of the motor control of the joint. Proprioception is defined as an ensemble of senses such as the senses of limb position and movement (also called kinesthesia), of tension or force, of effort and of balance. ${ }^{1314}$ The proprioceptors, receptors concerned with monitoring the body's actions, ${ }^{13}$ can be found in several structures throughout the body, including skin around 
joints, muscles, tendons, fascia, joint capsules and ligaments. $^{1415}$

Several tests have been developed to objectify the sensory or motor deficits that can be observed after ankle sprains. They are said to evaluate proprioception, but in reality they either assess somatosensation or motor control. The assessment of somatosensation usually involves testing movement detection or movement reproduction which requires by the person being tested the use of information coming from sensory receptors such as muscle spindles, Golgi tendon organs, joint receptors and cutaneous receptors from skin over the joints (ie, information from proprioceptors). On the other hand, assessment of motor control involves testing the performance during functional movement execution, which requires by the person being tested a timely integration of the information from the sensory receptors listed above with movement planning and execution (ie, requires sensorimotor integration). As a result, motor control tests actually assess the more global function of motor control and somatosensation processing during functional, active task. In brief, they make use of proprioceptive information, but also require motor output (eg, jumping or reaching tests). For all of these tests (somatosensation or motor control tests), this review asks which ones are valid, reliable, sensitive and clinically relevant to evaluate ankle function or the impact of sensorimotor deficits on lower limb motor control. Previous reviews published between 2010 and 2017 generally concluded that proprioceptive tests are reliable and valid, ${ }^{9}{ }^{16-18}$ but did not differentiate between tests assessing specifically proprioception or global motor control. To this date, it remains difficult for clinicians to know which test to use to highlight specific deficits following ankle sprains (such as motor or sensory deficits). Therefore, the first objective of this review was to categorise proprioceptive tests regarding their main outcome (motor control or somatosensation). Our second objective was to conduct a systematic review of the psychometric properties of these tests. These two objectives will contribute to determine which tests should be recommended for the clinics to assess sensory, motor or somatosensory processing deficits.

\section{MATERIALS AND METHODS}

This systematic review is registered on PROSPERO (CRD42019125827) and follows the Preferred Reporting Items for Systematic Reviews and Meta-Analyses guidelines.

\section{Description of included tests}

We searched the literature for tests used to evaluate ankle proprioception in patients with ankle instability or sprain. To be included in the present systematic review, a proprioceptive test had to have its psychometric properties (validity, reliability or responsiveness) evaluated in at least two articles. Based on these criteria, eight main groups of proprioceptive tests were included: Star

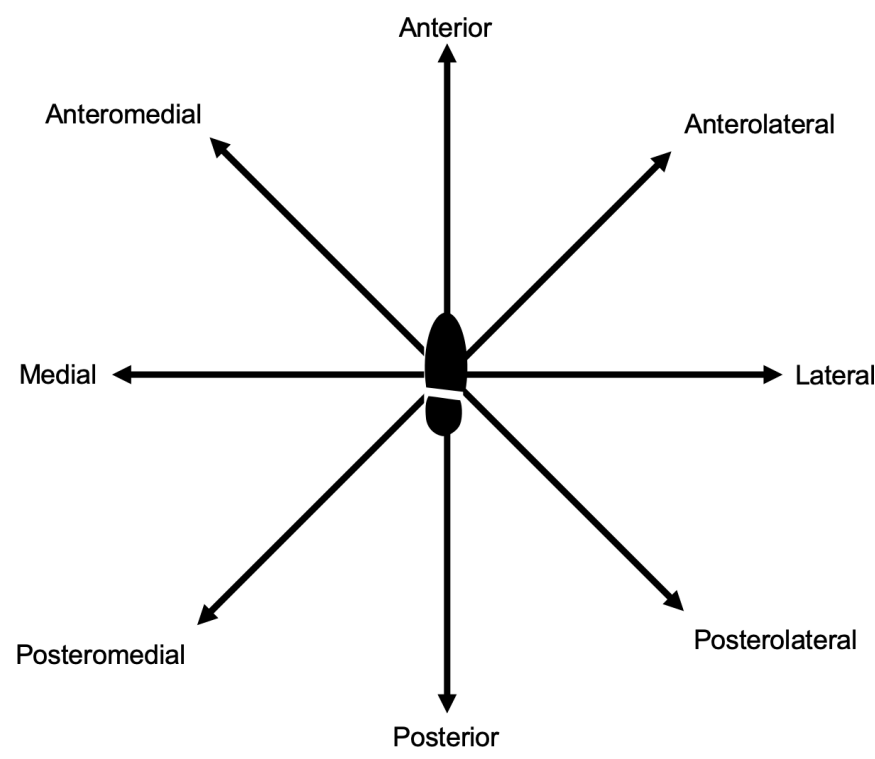

Figure 1 Representation of the Star Excursion Balance Test for the right weight-bearing limb.

Excursion Balance Test (SEBT), Threshold for Perception of Passive Movement (TPPM), Joint Position Sense (JPS), Hop Tests, Biodex Stability System (BSS), Limit of Stability (LoS), Balance Error Scoring System (BESS) and Time to Stabilisation (TTS).

\section{Star Excursion Balance test}

The SEBT has been developed to assess dynamic stability of healthy individuals or athletes or with people suffering from chronic ankle instability or functional ankle instability (FAI; type of instabilities including subjective instability, weakness or feeling of less functional ankle ${ }^{9}$ ). Participants have to stand on one leg and reach as far as they can on a star-shaped form on the ground with the free leg (figure 1). Complete description of this test or its simplified version is available in the literature. ${ }^{19} 20$

\section{Threshold for Perception of Passive Movement}

TPPM is a passive test that can be conducted with different apparatus, where participants are usually seated with one foot fixed to a pedal. Without seeing their foot, participants have to signal (by pressing a button or by saying yes / no) when they start to feel a passive movement at the ankle. ${ }^{21-24}$

\section{Joint Position Sense}

Several protocols have been proposed to assess JPS, either actively or passively. Briefly, the participant has to replicate the joint position as accurately as possible with the ipsilateral or contralateral extremity or describe the position verbally to an evaluator. Different paradigms have been described: active-to-active ${ }^{21}{ }^{25}$ passive-to-passive, ${ }^{23} 26$ passive-to-active 23 or passive-to-passive or passive-toactive. $^{33-39}$ Other options consist of moving the ankle passively in one direction and asking the participant to indicate the direction of the movement ${ }^{40-42}$ or using specific apparatus to actively test JPS. ${ }^{43} 44$ 


\section{Hop Tests}

More than 10 variations of the Hop Tests have been developed to evaluate coordination and joint stability ${ }^{3639}$ : Single and Triple Hop Test, ${ }^{36} 39456$ Lateral or Side-to-Side Hop Test, ${ }^{4748}$ Crossover Hop for Distance, ${ }^{45-48} 6$ m Timed Hop, ${ }^{36} 394546$ Cross 6 for Time ${ }^{363948}$ Multiple Hop Test (MHT), ${ }^{49-52}$ Agility Hop Test, ${ }^{53} 30 \mathrm{~m}$ Single-Leg Agility Hop Test, ${ }^{54}$ Figure-of-8 Test ${ }^{47} 4855$ and Square Hop Test. ${ }^{55}$ Depending on the particular hop test, the main variable can either be distance, time or number of errors.

\section{Biodex Stability System and Limit of Stability}

The BSS consists of a multidirectional platform that provides up to $20^{\circ}$ of surface tilt. The measure of postural stability includes the overall stability index, the anterior/ posterior and the medial/lateral stability scores. ${ }^{31} 325657$ The LoS can be measured in either bilateral or unilateral standing positions. It can be evaluated with the BSS or with a forceplate. ${ }^{58}$

\section{Balance Error Scoring System}

The BESS is a test including six conditions (three stances and two surfaces) in which participants have to stand unsupported with their eyes closed. The main variable is the number of errors. 5859

\section{Time to Stabilisation}

TTS can be performed by evaluating, using a motiontracking system, the response time to an external perturbation while the participant stands on a platform ${ }^{30}$ or by jumping forward and landing on one leg on a force plate while trying to maintain stability for a specific amount of time. ${ }^{3360-62}$

\section{Identification and selection of studies}

Four databases were searched from inception to April 2019: Medline, CINHAL, EMBase and SPORTDiscus. The following keywords were used: (propriocepti* OR kinesthes* OR kinaesthes* OR 'joint position sense' OR 'hop test*' OR biodex OR 'star excursion balance test' OR sebt OR 'Clinical Test of Sensory Interaction and Balance' OR ctsib). Since the review was meant to focus only on the ankle joint, the Boolean operator 'AND' and the keyword ankle were added. Finally, keywords specific to our outcomes were used in the equation: ('test-retest' OR 'test retest' OR outcome* OR validation OR assessment OR measur* OR validity OR sensitivity OR reliability OR 'standard error the mean' OR reproducibility OR evaluati* OR responsiveness). Each equation was adapted to the four databases selected in order to be as sensitive as possible in our search. The reference list of each included article was also screened to retrieve further articles. Included articles had to (1) study the psychometric properties (validity, reliability and responsiveness; see table 1 for definitions) of one of the ankle proprioceptive tests previously presented; (2) include healthy participants with whom tests have been assessed or developed; and (3) participants with ankle instability or ankle sprain since these tests are mainly
Table 1 Definitions of the psychometric properties

\section{Psychometric properties}

Validity

\section{Validity}

\section{Known-group}

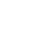

\begin{tabular}{|c|c|}
\hline Convergent & $\begin{array}{l}\text { The degree to which two measures } \\
\text { believed to reflect the same underlying } \\
\text { phenomenon will yield similar results } \\
\text { or will correlate highly. }\end{array}$ \\
\hline Reliability & $\begin{array}{l}\text { The degree to which the measurement } \\
\text { is free from measurement error. }\end{array}$ \\
\hline Intratester & $\begin{array}{l}\text { The consistency with which one rater } \\
\text { assigns scores to a single set of } \\
\text { responses on two or more occasions. }\end{array}$ \\
\hline Intertester & $\begin{array}{l}\text { The consistency among different } \\
\text { judges' ratings of the same participant } \\
\text { or response. }\end{array}$ \\
\hline Test-retest & $\begin{array}{l}\text { The ability of a measurement to be } \\
\text { repeated from one test occasion to } \\
\text { another. }\end{array}$ \\
\hline $\mathrm{ICC}$ & $\begin{array}{l}\text { A measure of relative reliability; } \\
\text { variance owing to the objects of } \\
\text { measurement divided by the total } \\
\text { variance (coefficient: }-1 \text { to } 1 \text { ). }\end{array}$ \\
\hline MDC & $\begin{array}{l}\text { An estimate of the smallest } \\
\text { change that can be detected by a } \\
\text { patient (same unit as the original } \\
\text { measurement), based on the SEM. }\end{array}$ \\
\hline Responsiveness & $\begin{array}{l}\text { The ability of an instrument to detect } \\
\text { change over time in the construct to } \\
\text { be measured. }\end{array}$ \\
\hline SRM & $\begin{array}{l}\text { Mean change in score divided by the } \\
\text { SD of the change in score. }\end{array}$ \\
\hline
\end{tabular}

ICC, intraclass correlation coefficient; MDC, minimal detectable change; SRM, standardised response mean.

used with this population. Exclusion criteria were articles regarding diagnosis or interventions, targeting participants suffering from a neurological disorder or looking at the effect of ageing. The languages of the articles were limited to French and English. Two evaluators (CD and MB-C) screened independently the titles and abstracts of all articles and selected the articles meeting the inclusion/exclusion criteria by consensus. A full-text review was then independently performed by each evaluator, and on reaching consensus, the articles were included in the present review. A third evaluator (J-SR) was present in case of disagreement between the two evaluators. 


\section{Methodological quality}

The methodological quality of all included studies were evaluated independently by two evaluators using a validated critical appraisal tool developed by Law and MacDermid. ${ }^{63}$ This instrument includes 12 items divided into five categories (study question, study design, measurements, analyses and recommendations). Each item is scored on a 3-point ordinal scale $(0,1$ and 2, with 0 being the lowest score). After the evaluation of all included articles, the evaluators met to reach a consensus. If a consensus could not be reached, a third evaluator (J-SR) would join the discussion to solve the disagreement. An intraclass correlation coefficient (ICC) was calculated to evaluate preconsensus inter-rater reliability of the total score on the critical appraisal tool. Studies were ranked regarding the score they were given, and this rank was considered in the conclusions. Level of evidence of included studies was defined according to the following criteria: low risk of bias for articles with a quality score over $80 \%$, moderate risk of bias for articles with a quality score between $60 \%$ and $80 \%$ and high risk of bias for articles with a quality score under $60 \%$.

\section{Data extraction and analysis}

Data extraction for each article was performed by two evaluators (MB-C and CD; each evaluating $50 \%$ of the included studies) using a standardised data collection form. Then, each evaluator corroborated or completed the other half of the extraction if data were found to be missing. Data regarding the construct validity (concurrent validity, convergent/divergent validity and know-group validity), reliability (intratester/intertester reliability, test-retest reliability, minimal detectable change) and responsiveness (standardised response mean (SRM), effect size (ES), clinically important difference) were extracted and summarised in the Results section. A weighted average (weighted by sample size) was calculated for reliability for a specific test when enough data were available. Correlations were considered strong when $\geqslant 0.70$, moderate when between 0.50 and 0.70 , and weak when $<0.50 .{ }^{64}$ For relative reliability, ICC $<0.50$ were categorised as poor, ICC between 0.50 and 0.75 were considered as moderate reliability, values between 0.75 and 0.90 indicate good reliability and ICC $\geqslant 0.90$ were categorised as excellent reliability. ${ }^{65}$ Finally, SRM and ES of $0.20,0.50$ and 0.80 or greater were chosen to represent small, moderate and large responsiveness, respectively. ${ }^{66}$

The body of evidence on which our recommendations were based were classified as strong, moderate, conflicting, limited and very limited. ${ }^{67}$

Strong evidence: multiple high quality (HQ) studies with consistent results, regardless of methodological heterogeneity.

Moderate evidence: multiple studies, including at least one HQ study; or multiples moderate quality (MQ) or good quality (GQ) studies; or multiple low quality (LQ) studies, homogeneous methodologies; always providing consistent results.

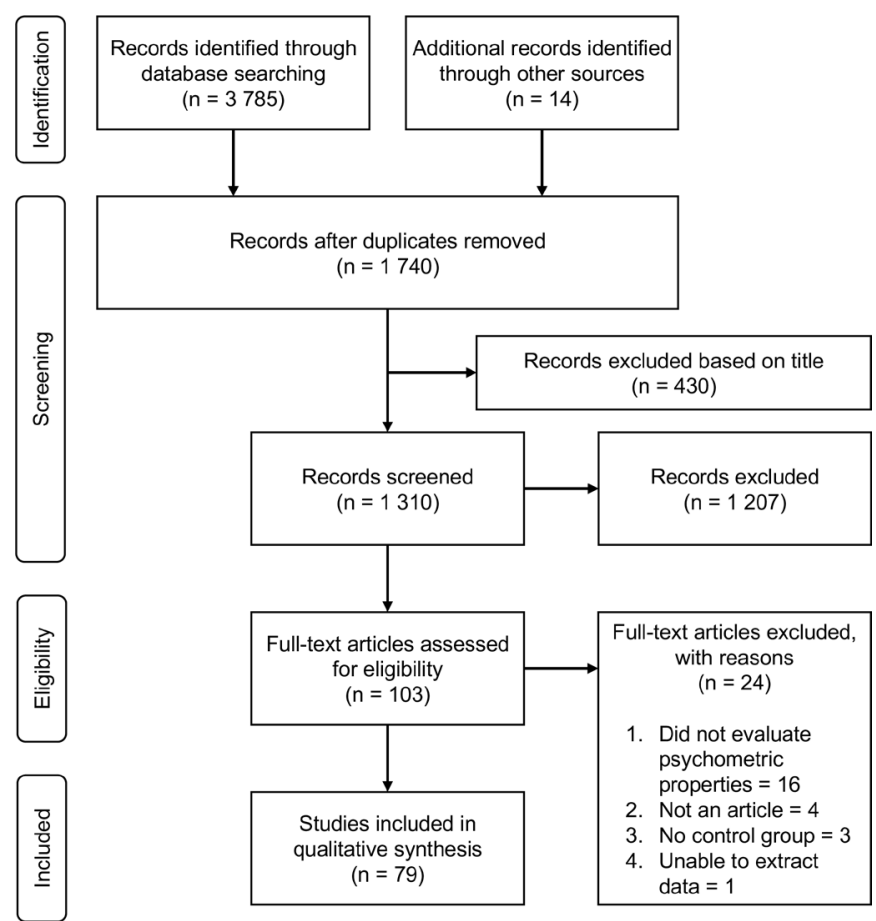

Figure 2 Flowchart describing the articles selection process.

Conflicting evidence: multiple studies regardless of the methodological quality, with inconsistent results.

Limited evidence: multiple studies, with heterogeneous methodologies and/or inconsistent results; or single GQ study or higher.

Very limited evidence: results from single $\mathrm{LQ}$ or $\mathrm{MQ}$ study.

\section{RESULTS}

Out of the 103 full-text articles assessed for eligibility, 79 articles were included (figure 2). The methodological quality of included studies ranged from $45 \%$ to $100 \%$, with $61 \%$ of the articles reaching or exceeding $80 \%$ on the critical appraisal tool. The preconsensus inter-rater reliability of the total score was good (ICC: $0.89,95 \%$ CI 0.82 to 0.92$)$. Descriptive information of the population such as age, sex and diagnosis are available in online supplementary file 1 alongside with the summary of the included studies.

\section{Categorisation of the reviewed tests}

Following the literature review, eight main groups of tests used to assess ankle proprioception were identified. As mentioned above, there is a discrepancy regarding the definition of proprioception and the outcome measured by these proprioceptive tests. Therefore, they were divided into two categories of tests with regard to their main outcome: motor control or somatosensation (online supplementary file 2).

\section{Characteristics of the studies}

Two types of validity were studied: know-group validity for the SEBT, ${ }^{19} 30616268-85$ TPPM, ${ }^{30} 86$ JPS, ${ }^{21} 25-353741-448788$ 
Hop Tests, ${ }^{47} 485052-5478798789-91$ BSS $^{57}$ and LoS, ${ }^{74}$ BESS $^{59}$ and $\mathrm{TTS}^{30} 33 \quad 6062$; and convergent validity for the SEBT,, 81828592 TPPM, ${ }^{22}$ JPS $^{35}{ }^{93}$ Hop Tests, ${ }^{82} 94$ BESS $^{58}$ and LoS. ${ }^{58}$ Furthermore, three types of reliability were evaluated: intratester, ${ }^{20} 263639$ 45-47 49-52 545582 95-102 intertester $^{20} \quad 38 \quad 95 \quad 96 \quad 99 \quad 101$ and test-retest reliability. $^{21} 23242834363942-445658606192$ Test-retest reliability is evaluated when no evaluator is necessary to execute the test; therefore, the evaluator does not influence the results. For responsiveness, only SRMs were evaluated in one study. ${ }^{99}$

\section{Validity}

Star Excursion Balance Test $(\mathrm{n}=23)$

Known-group validity

When comparing injured ankles with healthy ankles, the reach distance in the SEBT was smaller in the injured group for 16 articles out of 21. ${ }^{19}{ }^{30-81}$ When looking at the eight directions of the SEBT, the posterior-medial $(\mathrm{PM})^{68-737879}$ and anterior (Ant) ${ }^{306971-7380}$ were the most discriminative directions. ${ }^{68} 6971-737879$ Out of all directions, a majority of HQ studies and two low to moderate studies concluded that PM and Ant can discriminate between healthy and impaired groups.

\section{Convergent construct validity}

Fournier Belley et al found a strong correlation between the PM direction of the SEBT and the TPPM and a moderate correlation with the AM and Med directions. $^{92}$ Correlations were found between the SEBT and the Weight-Bearing Lunge Test (moderate correlation for anterior reach distance; $r=0.56),{ }^{75}$ between the SEBT and the Single-Limb Hop Test (SLHT) (weak correlation; $r=-0.303)^{82}$ and between the limb length and the reach distance for the SEBT (high correlation; $\mathrm{r}=0.70) .{ }^{81}$ A very weak correlation was present between the SEBT and static or dynamic balance tests on one leg. ${ }^{85}$

\section{Threshold for Perception of Passive Movement $(n=3)$}

Known-group validity

In one study, significant difference in TPPM between control and ankle sprain groups was observed, ${ }^{86}$ while another showed no difference between the groups. ${ }^{30}$

\section{Convergent construct validity}

One study found a significant correlation $(\mathrm{p}<0.001)$ between a higher threshold for TPPM and a short single-leg stand time. ${ }^{22}$

\section{Joint Position Sense $(\mathrm{n}=20)$}

\section{Known-group validity}

Thirteen out of 17 articles reported that JPS can discriminate between unstable ankles and healthy ankles, ${ }^{21}$ 25-27 $2934353742-448788$ while four others reported no significant differences. ${ }^{28} 303341$ Rein et al compared professional dancers or soccer players to amateur and a control group; JPS could discriminate these groups. ${ }^{31} 32$

\section{Convergent construct validity}

Active JPS highly correlates with static balance with the eyes closed. ${ }^{35}$ However, one study found that JPS evaluated using AMEDA apparatus was not correlated with passive-to-active JPS evaluated with the Biodex. ${ }^{93}$

Hop Tests $(\mathrm{n}=14)$

Known-group validity

The ability of Hop Tests to discriminate between different groups depends on the test and the comparison made, that is, comparing between two groups (eg, copers or acutely sprained and controls) or between the healthy and sprained ankle on the same participants. In general, most of the Hop Tests could not discriminate healthy and sprained ankles on the same participants. 47485548990 More variable results were found for the Single Hop ${ }^{475478798789}$ and Figure-8 Hop ${ }^{47490}$ tests with four studies out of seven ${ }^{78798287}$ and one out of three studies ${ }^{90}$ reporting that the tests were able to discriminate between groups. More consistent results were reported for the MHT where three studies showed a good ability to discriminate between healthy and sprained ankles. ${ }^{50} 5291$

\section{Convergent construct validity}

Ko et al reported that the Single Hop Test correlates with the SEBT (weak correlation; $r=-0.303$ ), ${ }^{82}$ while the Figure-of- 8 and Side Hop tests weakly correlate with the Functional Ankle Instability index (a questionnaire on functional instability) ( $\mathrm{r}=0.31$ and 0.35 , respectively), while no significant correlations were found for the SLHT. ${ }^{94}$ On the other hand, the SLHT moderately correlates with the SEBT. ${ }^{82}$

\section{Biodex Stability System and Limit of Stability $(\mathrm{n}=3)$ Known-group validity}

Perron et al reported that BSS can discriminate between healthy and unstable ankles. ${ }^{57}$ For LoS, Akbari et al compared the injured to the uninjured ankle in participants with ankle sprain and found no difference between the ankles. $^{74}$

\section{Convergent construct validity}

Alsalaheen et al reported no correlation between LoS and static balance. ${ }^{58}$

Balance Error Scoring System $(\mathrm{n}=2)$

Known-group validity

Docherty et al reported that participants with FAI scored significantly more total BESS errors than the control group. $^{59}$

\section{Convergent construct validity}

Alsalaheen et al reported no correlation between LoS and BESS. $^{58}$

Time to Stabilisation $(\mathrm{n}=4)$

Known-group validity

Three articles found a difference in the anterior-posterior direction between healthy and previously sprained ankle. 
Brown et al reported a shorter TTS in healthy participants. ${ }^{3360}$ However, Steib et al showed a smaller TTS in copers (athletes who successfully return to high-level sports activities and report normal function without persistent complaints) compared with healthy ankles. ${ }^{62}$ TTS has been shown to be shorter in healthy participants after an inversion perturbation compared with participants with ankle sprains. ${ }^{30}$

\section{Reliability}

Intratester reliability $(\mathrm{n}=23)$

Three tests have been studied for intratester reliability in healthy participants. All results and weighted averages, when available, are shown in table 2 . Among them, the SEBT showed good to excellent reliability, ${ }^{20} 82$ 95-101 depending on the direction used, with the medial direction presenting the highest ICCs. Minimal detectable change (MDC) of the SEBT in healthy controls varied between 6.38 (medial) and $9.24 \mathrm{~cm}$ (posterior-lateral). One article studied intratester reliability for JPS. ${ }^{26}$ In this study, the participant's ankle was moved passively at $30 \%$, $60 \%$ or $90 \%$ increments of the participant's total range of active ankle inversion. Participant then had to actively reposition the ankle in inversion or indicate when the target position was passively reached. ICC ranged from moderate to excellent (weighted average: $0.60-0.98$ ). For the hop tests, reliability varied depending on the test or outcome evaluated. Figure 8, side-to-side and triple crossover tests showed poor reliability (ICC: $0.27-0.43$ ), ${ }^{4755}$ MHT for errors (postural corrections) showed moderate reliability (ICC: 0.64$)^{49}$ and triple hop, $6 \mathrm{~m}$ timed hop and multiple hop for time tests had good reliability (ICC: $0.77-0.86) .{ }^{36} 39454649-5254$ Finally, 7 out of 14 Hop Tests showed an excellent reliability, with the single hop test scoring the highest (ICC ranging between 0.92 and 0.98)..$^{364546545582102}$ MDCs of each test are shown in table 2.

\section{Intertester reliability $(\mathrm{n}=6)$}

Intertester reliability has only been studied for SEBT and JPS in healthy participants (table 3). As for intratester, the results varied depending on the direction reached for the SEBT. In general, SEBT has good reliability (weighted average 0.79-0.90), , ${ }^{20596100101}$ with the posterior-medial direction presenting the highest weighted ICCs. Its MDC varies between $8.3 \mathrm{~cm}$ (anterior) and $10.9 \mathrm{~cm}$ (posterior). As for the JPS, one study evaluated the intertester reliability and its MDC. ${ }^{38}$ Intertester variability ranged from poor (ICC: 0.03) to good (ICC: 0.87), depending on the conditions the test was done. When the test was done passively at $15^{\circ}$ of eversion, JPS presented the highest weighted ICCs (ICC: 0.87). The same variability was present for MDC, going from $0.08^{\circ}$ up to $2.4^{\circ}$.

Test-retest reliability $(n=15)$

Test-retest reliability has been assessed in healthy participants for TPPM, ${ }^{21} 2324 \mathrm{JPS},{ }^{21} 232834363942-4492 \mathrm{BSS}^{56} \mathrm{LoS}^{58}$ and TTS ${ }^{601}$ All available results are presented in table 4 .
TPPM shows excellent test-retest reliability (ICC: 0.92 0.94), except for dorsiflexion (ICC: 0.81). Moreover, the MDC for TPPM ranges from $0.58^{\circ}$ (plantar flexion) to $1.14^{\circ}$ (eversion). Different protocols have been used to evaluate JPS. In general, JPS showed good test-retest reliability (weighted average 0.83 ), with ICC between 0.60 and 0.98 and an MDC between $0.03^{\circ}$ and $2.9^{\circ}$ (weighted average $1.1^{\circ}$ ). The most reliable method seems to be the one used by Sekir et al that consist in passive-to-passive reproduction of joint position at $10^{\circ}$ and $20^{\circ}$ of inversion at a peak velocity of $1 \%$ s. This method showed an ICC of 0.98 at $20^{\circ}$ of inversion and 0.94 at $10^{\circ}$ of inversion. BSS has a good reliability (ICC of 0.76 in medial-lateral and 0.86 in anterior-posterior), while LoS showed moderate to excellent reliability (ICC: $0.73-0.96$ ). Finally, TTS has ICC varying from 0.68 in anterior-posterior and 0.86 in medial-lateral, indicating moderate to good test-retest reliability.

\section{Responsiveness}

The responsiveness has only been tested for the SEBT $(\mathrm{n}=1)$. Amacker et al found SRM values for the AM, Med and PM of 0.64, 1.19 and 1.09, respectively. The modified version of the SEBT showed similar SRM (AM: 0.73, Med: 1.07 and PM: 1.62).

\section{DISCUSSION}

The first objective of this study was to categorise the proprioceptive tests studied in the literature regarding their main outcome (motor control or somatosensation). As mentioned in the Introduction section, the term 'proprioception' has been defined by the original authors of the included studies to describe more than one construct assessed by their test. We therefore categorised the eight main groups of tests into two categories: motor control and somatosensation tests. These two categories were selected to highlight the physiological requirements that are primarily assessed in these tests.

For example, to perform SEBT or Hop Tests, significant motor planning and sensory integration are required (both of them being part of motor control). Motor control is the ability to regulate or direct the mechanisms essentials to movement. ${ }^{103}$ Based on that, SEBT or Hop Tests evaluate motor control, or global sensorimotor integration rather than proprioception specifically. It is also important to note here that ankle range of motion can affect SEBT performance as stiffness at the ankle joint has been shown to affect the result for the anterior direction. 104105

However, as it is not possible to assess specifically proprioceptors without taking into account tactile information, it would be more accurate to describe other tests such as JPS or TPPM as more somatosensation tests. For these tests, there is less evidence that motor control is involved when participants have to passively position their ankle at a given angle.

It is important to notice that three directions of the SEBT are moderately to strongly correlated with TPPM. 


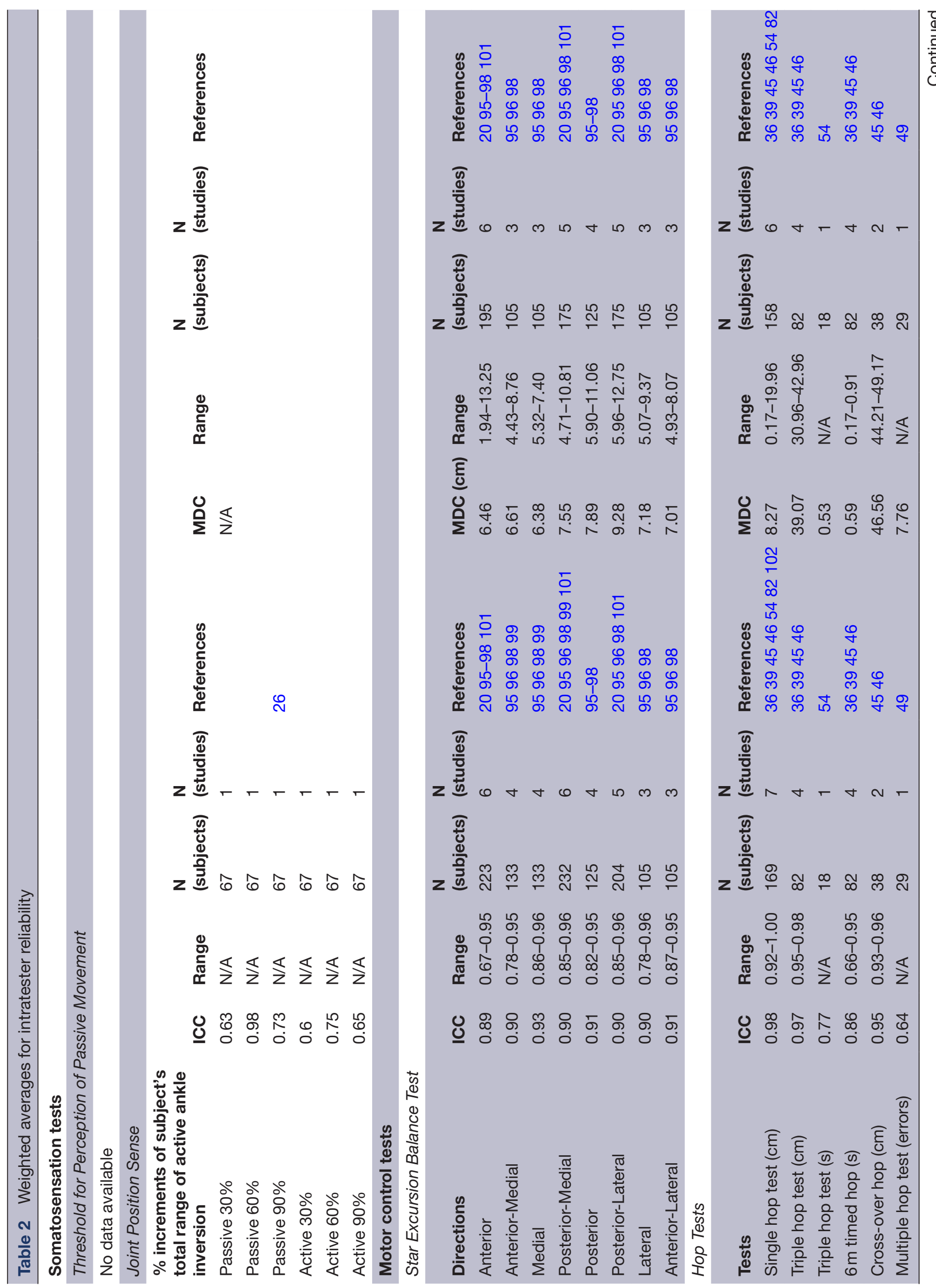




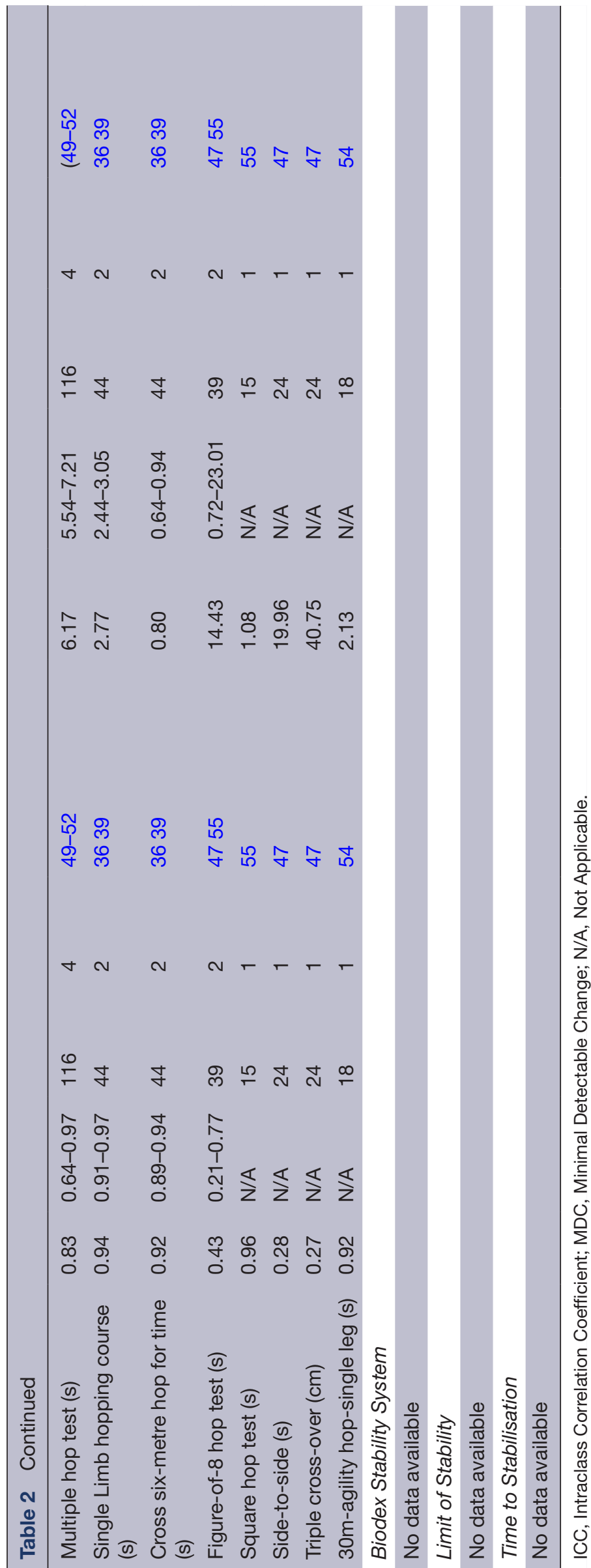




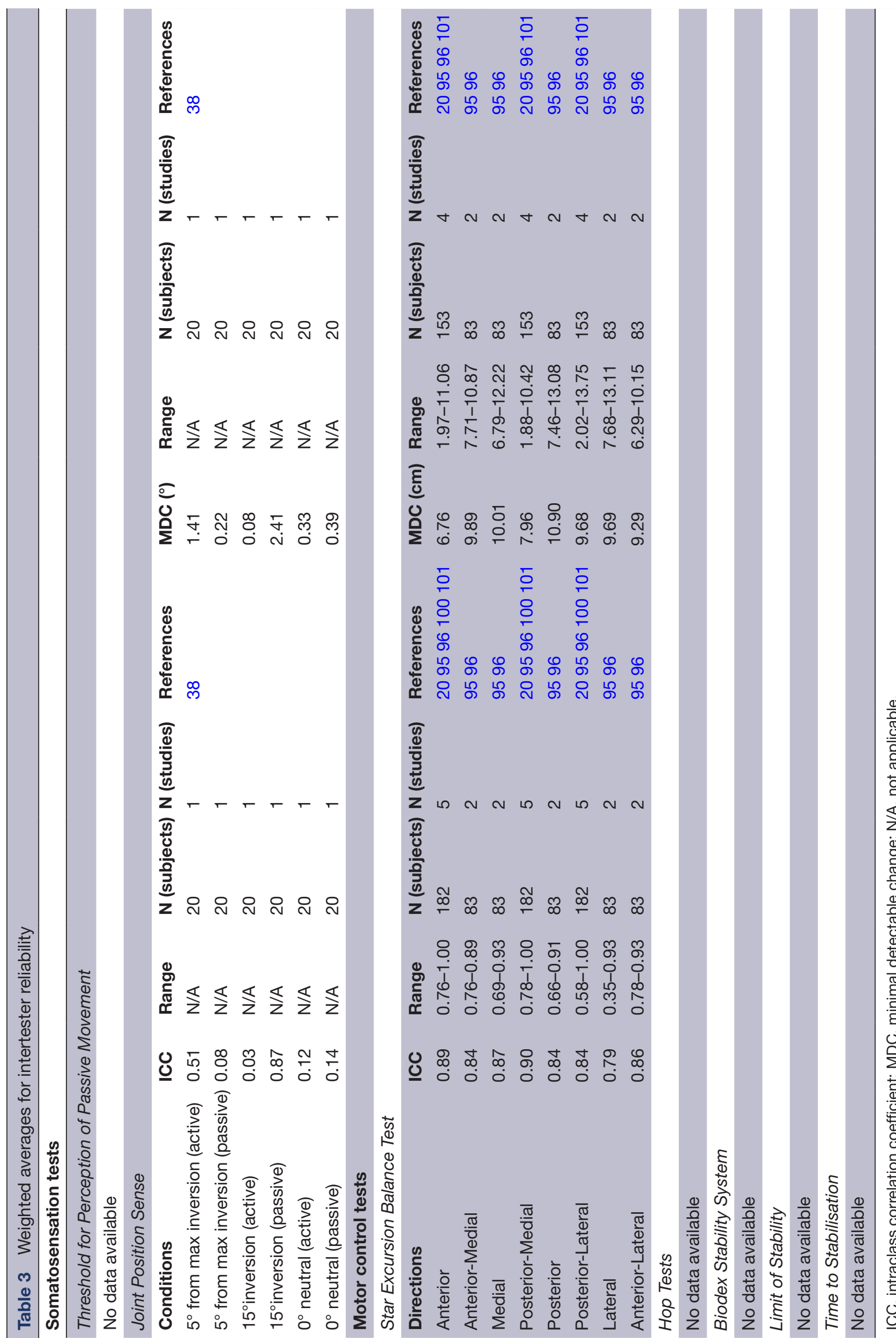




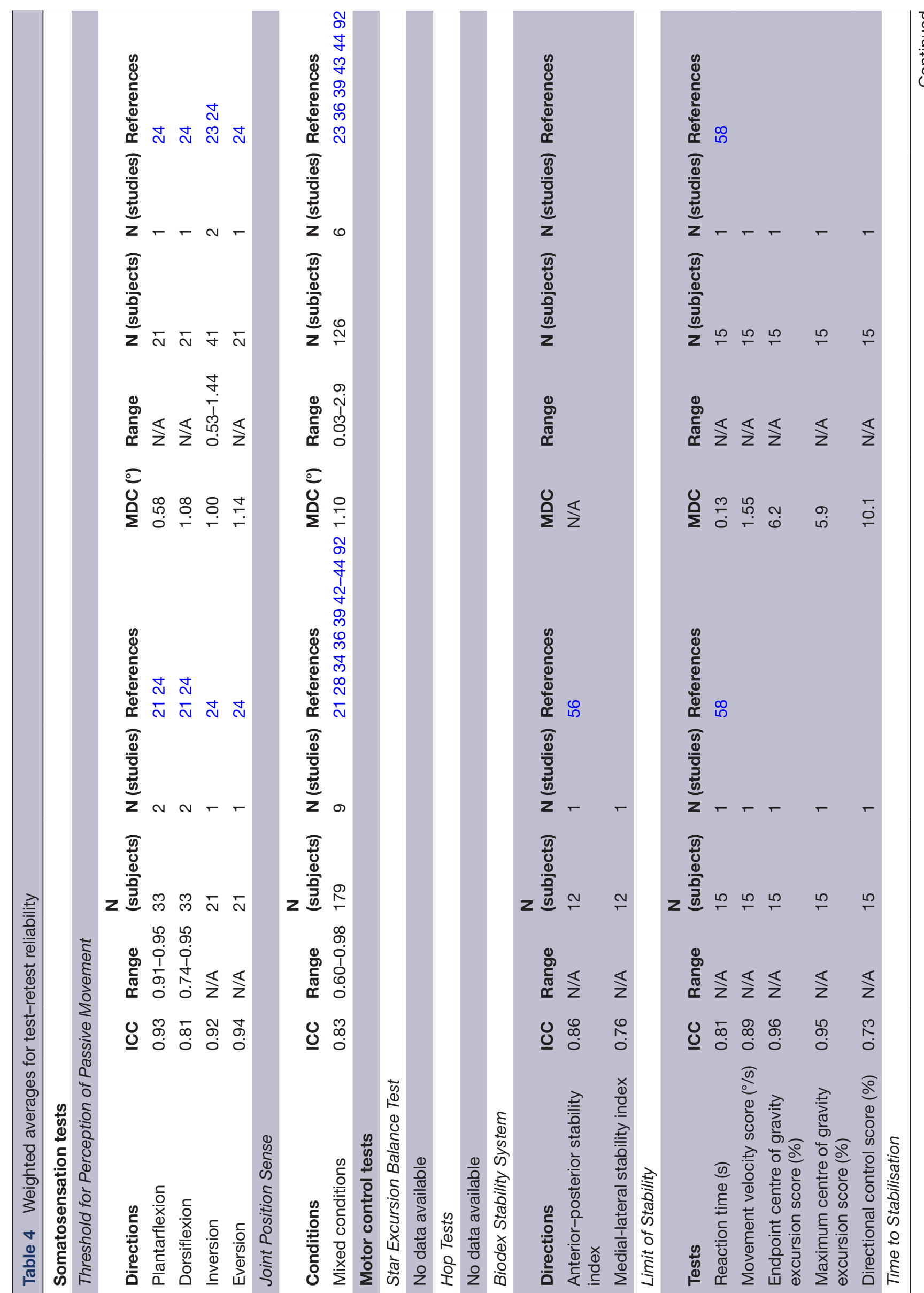




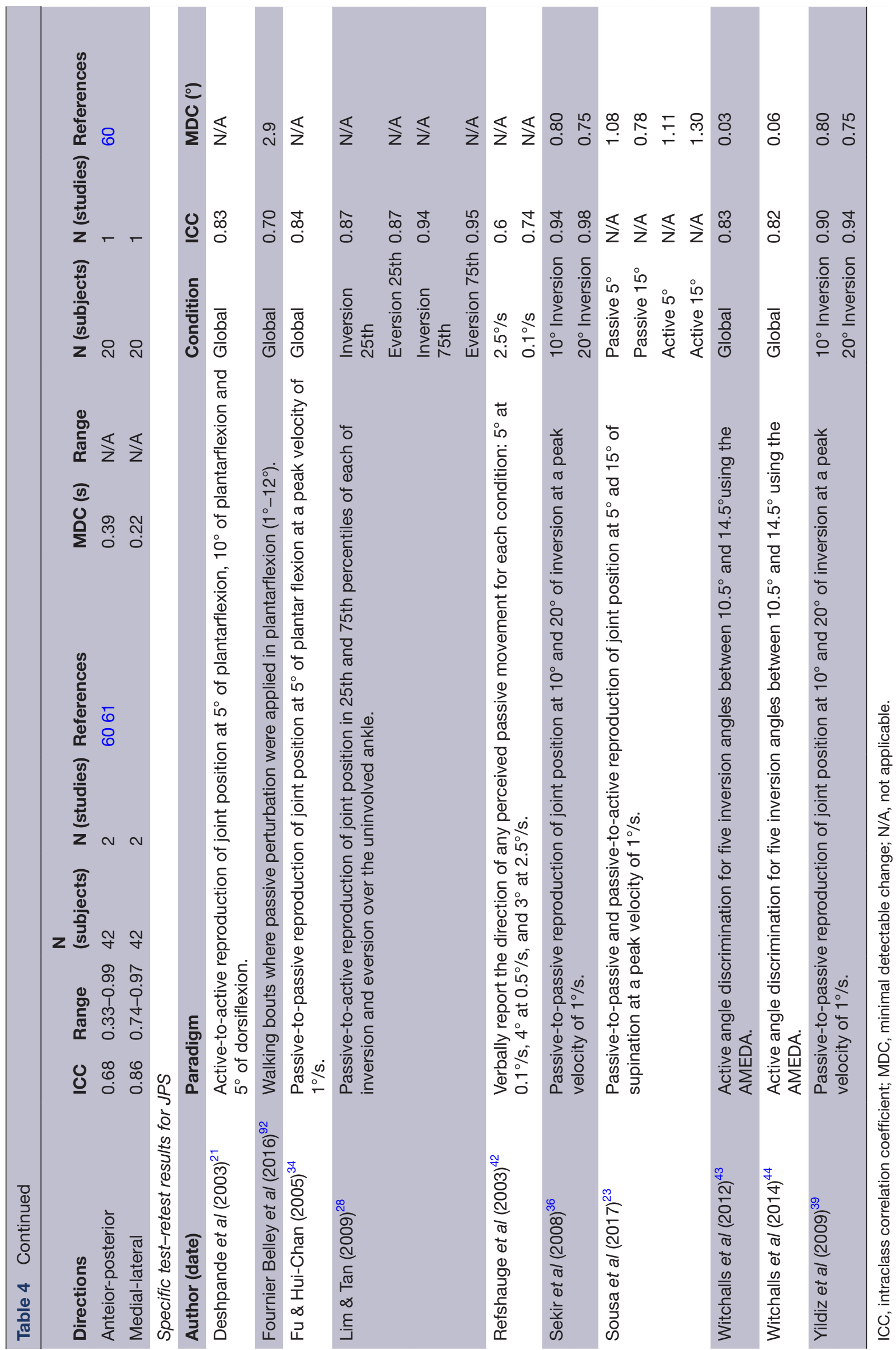


This means that these tests show similarities, despite addressing different constructs. We can conclude that considering these similarities, motor control and somatosensation are two related constructs, as somatosensation is fundamental for an adequate motor control. ${ }^{106}$

When looking at the included tests, motor control tests are mainly performed dynamically, while tests looking specifically at somatosensation processing tend to be more static. However, there is sometimes a need to assess somatosensation processing during dynamic tasks, where proprioception is further important to regulate the neural control of movement. ${ }^{107-109}$ In the study of Fournier-Belley $e t a l^{92}$ a robotised orthosis was used to test somatosensation processing during walking. Even if the psychometric properties of this orthosis were assessed in only one study, the experimental approach allowed the researchers to assess the sense of movement in a design similar to the TPPM, but during a functional task such as walking. Further studies should therefore consider testing somatosensation processing (eg, kinesthesia) during movement execution, when possible.

The second objective of this study was to systematically review the literature on the psychometric properties of tests commonly used to assess ankle proprioception following ankle sprain and ankle instability. Seventy-nine studies were included with a mean methodological score of $81.4 \%$. Only $12 \%$ of included studies presented either a moderate to high risks of bias. ${ }^{21} 2629535659879499$ Our main findings suggest that there is strong evidence that the SEBT is a valid, reliable and responsive test to assess ankle motor control, while moderate evidence suggests that TPPM and JPS are valid and reliable tests to assess ankle somatosensation.

As for the Hop Tests, there is conflicting evidence for SLHT (discriminant ${ }^{78} \quad 798287$; not discriminant ${ }^{47} 5489$ ) and limited evidence for MHT for time, ${ }^{50}$ meaning that they might be able to discriminate between groups while having good (MHT) ${ }^{495052}$ to excellent (SLHT) 363945465482102 intratester reliability. Regarding these results, MHT should be prioritised over the other Hop Tests. As for the last four tests, TTS, LoS, BESS and BSS, their psychometric properties have been less studied and therefore more HQ studies should be done before being able to give strong recommendations. The data available suggest that, between these four tests, TTS is the most discriminant, while LoS is the most reliable. Responsiveness has been assessed only for the SEBT, making it hard to conclude on this psychometric property for the other tests. It would therefore be important to address this aspect in further HQ studies.

Based on its psychometric properties, the SEBT is recommended to assess motor control at the ankle in clinical practice. As already mentioned, this test is easy-to-use in clinical settings ${ }^{16}$ as little equipment and training are required to perform this test. Moreover, there is strong evidence that this test is discriminant ${ }^{19} 306870717375-77$ and that three of its directions (PM, AM and Med) are moderately to strongly correlated with TPPM. ${ }^{92}$ Because of its high reliability and responsiveness, this test could also be used for the follow-up of patients.

Based on the two categories presented in online supplementary file 2, we would recommend to clinicians who specifically want to assess ankle somatosensation to select the JPS. By using a protocol similar to Boyle and Negus ${ }^{26}$ or Nakasa et al, ${ }^{29}$ there is moderate evidence that clinicians will have valid and reliable results if the test is performed passively at $60 \%$ increments of the subject's total range of active ankle inversion. ${ }^{26}$ However, it is important to emphasise that JPS is highly reliable when performed in a passive-to-passive way ${ }^{36} 394344$ and should therefore be used that way. On the downside, there is discrepancy in the literature concerning JPS validity (discriminant $^{2125-272934353742-448788}$ or not $^{28} 303341$ ). Since validity is the degree to which an instrument measures the construct(s) it purports to measure, the discrepancy regarding these data could be related to the use of the task itself. As mentioned before, if a JPS protocol was performed actively versus passively, the neural requirements can differ and this could directly impact the validity. Moreover, the differences in execution regarding speed and angle could affect its validity. For clinics that can afford more expensive apparatus, like a stationary dynamometer, TPPM could identify sprains (conflicting to moderate evidence) while having good to excellent reliability.

Previous systematic reviews have looked at motor control or somatosensation tests for the ankle and knee. Their main findings were similar to ours: TTS, ${ }^{9} \mathrm{JPS},{ }^{9} \mathrm{MHT}^{18}$ and SEBT $^{916-18}$ are valid tests that can discriminate between stable and unstable ankles. As in the present review, they also concluded that there was a need for more standard protocols to eventually provide stronger clinical recommendations. ${ }^{17} 18$ The main novelty of the present review is that we differentiate somatosensation tests from those assessing motor control. Regrouping test under the right category (motor control vs somatosensation) could potentially help the clinical decision-making process regarding the deficits clinicians want to address. Moreover, this review included more studies than previous systematic reviews (79 articles vs a maximum of 60 articles). Finally, most of the previous reviews studied various categories (such as JPS, SEBT and TTS ${ }^{9}$; the SEBT ${ }^{16}$ or SEBT and Hop Tests ${ }^{1718}$ ) of ankle proprioceptive tests, without addressing all of the categories presented in this review.

Our review also has some limitations. First, somatosensation tests that had been studied in only one paper were not included, as it would have been difficult to conclude on their validity or reliability. Also, the great variability in test protocols made it difficult to express clear clinical recommendations to pinpoint the most valid and reliable test as they could be administered in various ways.

\section{CONCLUSION}

In conclusion, when looking at the literature, one can notice that most of the tests are said to assess proprioception, even though some will primarily give insights on the participant's motor control capacity. We therefore suggest 
to categorise tests according to their primary outcome (ie, motor control vs somatosensation). With regard to the second objective, the SEBT is an easy-to-use clinical test that gives valid, reliable and responsive information about the participant's motor control, while giving insights at proprioceptive capacities. This test can be used to discriminate between stable and unstable ankles in a clinical setting and the results can also be used for participant follow-ups. Also, there is moderate evidence that JPS could be a good alternative (valid and reliable when performed passively at $60 \%$ increments of the subject's total range of active ankle inversion) to the SEBT when clinicians want to specifically assess somatosensation.

Contributors MB-C and J-SR conceived and designed this study. MB-C and CD searched, extracted and analysed data. The manuscript was written by MB-C and $\mathrm{CD}$. All authors contributed to reviewing the study outcomes and approved the final version of the manuscript.

Funding MB-C and CD received a scholarship from Fonds de recherche du Québec - Santé (FRQS); J-SR was supported by a salary award from the Canadian Institutes of Health Research (CIHR).

Competing interests None declared.

Patient consent for publication Not required

Provenance and peer review Not commissioned; externally peer reviewed.

Data availability statement All data relevant to the study are included in the article or uploaded as supplementary information.

Open access This is an open access article distributed in accordance with the Creative Commons Attribution 4.0 Unported (CC BY 4.0) license, which permits others to copy, redistribute, remix, transform and build upon this work for any purpose, provided the original work is properly cited, a link to the licence is given, and indication of whether changes were made. See: https://creativecommons.org/ licenses/by/4.0/.

ORCID iD

Michaël Bertrand-Charette http://orcid.org/0000-0002-5479-4278

\section{REFERENCES}

1 Davidson PL, Chalmers DJ, Wilson BD, et al. Lower limb injuries in New Zealand defence force personnel: descriptive epidemiology. Aust N Z J Public Health 2008;32:167-73.

2 Doherty C, Delahunt E, Caulfield B, et al. The incidence and prevalence of ankle sprain injury: a systematic review and metaanalysis of prospective epidemiological studies. Sports Med 2014;44:123-40.

3 Fong DT-P, Hong Y, Chan L-K, et al. A systematic review on ankle injury and ankle sprain in sports. Sports Med 2007;37:73-94.

4 Hootman JM, Dick R, Agel J. Epidemiology of collegiate injuries for 15 sports: summary and recommendations for injury prevention initiatives. J Athl Train 2007:42:311-9.

5 Roos KG, Kerr ZY, Mauntel TC, et al. The epidemiology of lateral ligament complex ankle Sprains in national collegiate athletic association sports. Am J Sports Med 2017;45:201-9.

6 Shah S, Thomas AC, Noone JM, et al. Incidence and cost of ankle Sprains in United States emergency departments. Sports Health 2016;8:547-52.

7 Ivins D. Acute ankle sprain: an update. Am Fam Physician 2006;74:1714-20.

8 van Rijn RM, van Os AG, Bernsen RMD, et al. What is the clinical course of acute ankle sprains? A systematic literature review. Am J Med 2008:121:324-31.

9 Munn J, Sullivan SJ, Schneiders AG. Evidence of sensorimotor deficits in functional ankle instability: a systematic review with meta-analysis. J Sci Med Sport 2010;13:2-12.

10 Willems T, Witvrouw E, Verstuyft J, et al. Proprioception and muscle strength in subjects with a history of ankle Sprains and chronic instability. J Athl Train 2002;37:487-93.

11 Bastien M, Moffet $\mathrm{H}$, Bouyer LJ, et al. Alteration in global motor strategy following lateral ankle sprain. BMC Musculoskelet Disord 2014;15:436.
12 Hertel J. Sensorimotor deficits with ankle sprains and chronic ankle instability. Clin Sports Med 2008;27:353-70.

13 Proske $U$. What is the role of muscle receptors in proprioception? Muscle Nerve 2005:31:780-7.

14 Proske U, Gandevia SC. The proprioceptive senses: their roles in signaling body shape, body position and movement, and muscle force. Physiol Rev 2012;92:1651-97.

15 Grigg P. Peripheral neural mechanisms in proprioception. J Sport Rehabil 1994;3:2-17.

16 Gribble PA, Hertel J, Plisky P. Using the Star excursion balance test to assess dynamic postural-control deficits and outcomes in lower extremity injury: a literature and systematic review. J Athl Train 2012;47:339-57.

17 Hegedus EJ, McDonough SM, Bleakley C, et al. Clinician-friendly lower extremity physical performance tests in athletes: a systematic review of measurement properties and correlation with injury. Part 2--the tests for the hip, thigh, foot and ankle including the star excursion balance test. Br J Sports Med 2015;49:649-56.

18 Rosen AB, Needle AR, Ko J. Ability of functional performance tests to identify individuals with chronic ankle instability: a systematic review with meta-analysis. Clin J Sport Med 2019;29:509-522.

19 Olmsted LC, Carcia CR, Hertel J, et al. Efficacy of the Star excursion balance tests in detecting reach deficits in subjects with chronic ankle instability. J Athl Train 2002;37:501-6.

20 Plisky PJ, Gorman PP, Butler RJ, et al. The reliability of an instrumented device for measuring components of the star excursion balance test. N Am J Sports Phys Ther 2009;4:92-9.

21 Deshpande N, Connelly DM, Culham EG, et al. Reliability and validity of ankle proprioceptive measures. Arch Phys Med Rehabil 2003;84:883-9.

22 Deshpande N, Simonsick E, Metter EJ, et al. Ankle proprioceptive acuity is associated with objective as well as self-report measures of balance, mobility, and physical function. Age 2016;38:53.

23 Sousa ASP, Leite J, Costa B, et al. Bilateral proprioceptive evaluation in individuals with unilateral chronic ankle instability. $J$ Athl Train 2017;52:360-7.

24 Sun W, Song Q, Yu B, et al. Test-retest reliability of a new device for assessing ankle joint threshold to detect passive movement in healthy adults. J Sports Sci 2015;33:1667-74.

25 Lin C-H, Chiang S-L, Lu L-H, et al. Validity of an ankle joint motion and position sense measurement system and its application in healthy subjects and patients with ankle sprain. Comput Methods Programs Biomed 2016;131:89-96.

26 Boyle J, Negus V. Joint position sense in the recurrently Sprained ankle. Aust J Physiother 1998;44:159-63.

27 Kim C-Y, Choi J-D, Kim H-D. No correlation between joint position sense and force sense for measuring ankle proprioception in subjects with healthy and functional ankle instability. Clin Biomech 2014:29:977-83.

28 Lim ECW, Tan MH. Side-to-side difference in joint position sense and kinesthesia in unilateral functional ankle instability. Foot Ankle Int 2009;30:1011-7.

29 Nakasa T, Fukuhara K, Adachi N, et al. The deficit of joint position sense in the chronic unstable ankle as measured by inversion angle replication error. Arch Orthop Trauma Surg 2008;128:445-9.

30 Pourkazemi F, Hiller C, Raymond J, et al. Using balance tests to discriminate between participants with a recent index lateral ankle sprain and healthy control participants: a cross-sectional study. J Athl Train 2016;51:213-22.

31 Rein S, Fabian T, Weindel S, et al. The influence of playing level on functional ankle stability in soccer players. Arch Orthop Trauma Surg 2011;131:1043-52.

32 Rein S, Fabian T, Zwipp H, et al. Postural control and functional ankle stability in professional and amateur dancers. Clin Neurophysiol 2011;122:1602-10.

33 Brown C, Ross S, Mynark R, et al. Assessing functional ankle instability with joint position sense, time to stabilization, and electromyography. J Sport Rehabil 2004;13:122-34.

34 Fu ASN, Hui-Chan CWY. Ankle joint proprioception and postural control in basketball players with bilateral ankle sprains. Am J Sports Med 2005;33:1174-82.

35 Lee A, Lin W, Huang C. Impaired proprioception and poor static postural control in subjects with functional instability of the ankle. $J$ Exerc Sci Fit 2006;4:117-25.

36 Sekir U, Yildiz Y, Hazneci B, et al. Reliability of a functional test battery evaluating functionality, proprioception, and strength in recreational athletes with functional ankle instability. Eur J Phys Rehabil Med 2008;44:407-15.

37 Switlick T, Kernozek TW, Meardon S. Differences in joint-position sense and vibratory threshold in runners with and without a history of overuse injury. J Sport Rehabil 2015;24:6-12. 
38 Szczerba JE, Bernier JN, Perrin DH, et al. Intertester reliability of active and passive ankle joint position sense testing. J Sport Rehabil 1995;4:282-91.

39 Yildiz Y, Sekir U, Hazneci B, et al. Reliability of a functional test battery evaluating functionality, proprioception and strength of the ankle joint. Turk J Med Sci 2009;39:115-23.

40 de Jong A, Kilbreath SL, Refshauge KM, et al. Performance in different proprioceptive tests does not correlate in Ankles with recurrent sprain. Arch Phys Med Rehabil 2005;86:2101-5.

41 Refshauge KM, Kilbreath SL, Raymond J. The effect of recurrent ankle inversion sprain and taping on proprioception at the ankle. Med Sci Sports Exerc 2000;32:10-15.

42 Refshauge KM, Kilbreath SL, Raymond J. Deficits in detection of inversion and eversion movements among subjects with recurrent ankle sprains. J Orthop Sports Phys Ther 2003;33:166-76.

43 Witchalls J, Waddington G, Blanch P, et al. Ankle instability effects on joint position sense when stepping across the active movement extent discrimination apparatus. J Athl Train 2012;47:627-34.

44 Witchalls JB, Waddington G, Adams R, et al. Chronic ankle instability affects learning rate during repeated proprioception testing. Phys Ther Sport 2014;15:106-11.

45 Bolgla LA, Keskula DR. Reliability of lower extremity functional performance tests. J Orthop Sports Phys Ther 1997;26:138-42.

46 Ross MD, Langford B, Whelan PJ. Test-retest reliability of 4 singleleg horizontal hop tests. J Strength Cond Res 2002;16:617-22.

47 Wikstrom EA, Tillman MD, Chmielewski TL, et al. Self-assessed disability and functional performance in individuals with and without ankle instability: a case control study. J Orthop Sports Phys Ther 2009;39:458-67.

48 Madsen LP, Hall EA, Docherty CL. Assessing outcomes in people with chronic ankle instability: the ability of functional performance tests to measure deficits in physical function and perceived instability. J Orthop Sports Phys Ther 2018;48:372-80.

49 Eechaute C, Bautmans I, De Hertogh W, et al. The multiple hop test: a discriminative or evaluative instrument for chronic ankle instability? Clin J Sport Med 2012;22:228-33.

50 Eechaute C, Vaes P, Duquet W. Functional performance deficits in patients with CAl: validity of the multiple hop test. Clin J Sport Med 2008;18:124-9.

51 Eechaute C, Vaes P, Duquet W. The chronic ankle instability scale: Clinimetric properties of a multidimensional, patient-assessed instrument. Phys Ther Sport 2008;9:57-66.

52 Eechaute C, Vaes P, Duquet W. The dynamic postural control is impaired in patients with chronic ankle instability: reliability and validity of the multiple hop test. Clin J Sport Med 2009;19:107-14.

53 Demeritt KM, Shultz SJ, Docherty CL, et al. Chronic ankle instability does not affect lower extremity functional performance. $J$ Athl Train 2002;37:507-11.

54 Worrell TW, Booher LD, Hench KM. Closed kinetic chain assessment following inversion ankle sprain. J Sport Rehabil 1994;3:197-203.

55 Tankevičius G, Lankaitė D, Kriščiūnas A, et al. Early isometric eversion and inversion changes after acute ankle Sprains. Educ Phys Train Sport 2013;91:53-61.

56 Cachupe WJC, Shifflett B, Kahanov L, et al. Reliability of Biodex balance system measures. Meas Phys Educ Exerc Sci 2001;5:97-108

57 Perron M, Hébert LJ, McFadyen BJ, et al. The ability of the Biodex stability system to distinguish level of function in subjects with a second-degree ankle sprain. Clin Rehabil 2007;21:73-81.

58 Alsalaheen B, Haines J, Yorke A, et al. Reliability and construct validity of limits of stability test in adolescents using a portable Forceplate system. Arch Phys Med Rehabil 2015;96:2194-200.

59 Docherty CL, Valovich McLeod TC, Shultz SJ. Postural control deficits in participants with functional ankle instability as measured by the balance error scoring system. Clin J Sport Med 2006;16:203-8.

60 Brown CN, Mynark R. Balance deficits in recreational athletes with chronic ankle instability. J Athl Train 2007:42:367-73.

61 Meardon S, Klusendorf A, Kernozek T. Influence of injury on dynamic postural control in runners. Int J Sports Phys Ther 2016;11:366-77.

62 Steib S, Hentschke C, Welsch G, et al. Effects of fatiguing treadmill running on sensorimotor control in athletes with and without functional ankle instability. Clin Biomech 2013;28:790-5.

63 Law MC, MacDermid J. Evidence-Based rehabilitation: a guide to practice. Slack Incorporated, 2008.

64 Mukaka MM. Statistics corner: a guide to appropriate use of correlation coefficient in medical research. Malawi Med $J$ 2012;24:69-71.
65 Koo TK, Li MY. A guideline of selecting and reporting intraclass correlation coefficients for reliability research. J Chiropr Med 2016;15:155-63.

66 Husted JA, Cook RJ, Farewell VT, et al. Methods for assessing responsiveness: a critical review and recommendations. J Clin Epidemiol 2000;53:459-68.

67 van Tulder M, Furlan A, Bombardier C, et al. Updated method guidelines for systematic reviews in the Cochrane collaboration back review group. Spine 2003;28:1290-9.

68 Hertel J, Braham RA, Hale SA, et al. Simplifying the star excursion balance test: analyses of subjects with and without chronic ankle instability. J Orthop Sports Phys Ther 2006;36:131-7.

69 Kalichman L, Lachman H, Freilich N. Long-term impact of ankle sprains on postural control and fascial densification. J Bodyw Mov Ther 2016;20:914-9.

70 Bastien M, Moffet H, Bouyer L, et al. Concurrent and discriminant validity of the StAR excursion balance test for military personnel with lateral ankle sprain. J Sport Rehabil 2014:23:44-55.

71 Doherty C, Bleakley C, Hertel J, et al. Dynamic balance deficits 6 months following first-time acute lateral ankle sprain: a laboratory analysis. J Orthop Sports Phys Ther 2015;45:626-33.

72 Doherty C, Bleakley C, Hertel J, et al. Dynamic balance deficits in individuals with chronic ankle instability compared to ankle sprain copers 1 year after a first-time lateral ankle sprain injury. Knee Surg Sports Traumatol Arthrosc 2016;24:1086-95.

73 Doherty C, Bleakley CM, Hertel J, et al. Laboratory measures of postural control during the star excursion balance test after acute first-time lateral ankle sprain. J Athl Train 2015;50:651-64.

74 Akbari $\mathrm{M}$, Karimi $\mathrm{H}$, Farahini $\mathrm{H}$, et al. Balance problems after unilateral lateral ankle sprains. J Rehabil Res Dev 2006;43:819-23.

75 Hoch MC, Staton GS, Medina McKeon JM, et al. Dorsiflexion and dynamic postural control deficits are present in those with chronic ankle instability. J Sci Med Sport 2012;15:574-9.

76 Pionnier R, Découfour N, Barbier F, et al. A new approach of the star excursion balance test to assess dynamic postural control in people complaining from chronic ankle instability. Gait Posture 2016;45:97-102.

77 Plante JE, Wikstrom EA. Differences in clinician-oriented outcomes among controls, copers, and chronic ankle instability groups. Phys Ther Sport 2013;14:221-6.

78 Ko J, Rosen AB, Brown CN. Functional performance deficits in adolescent athletes with a history of lateral ankle sprain(s). Phys Ther Sport 2018;33:125-32.

79 Ko J, Rosen AB, Brown CN. Functional performance tests identify lateral ankle sprain risk: a prospective pilot study in adolescent soccer players. Scand J Med Sci Sports 2018;28:2611-6.

80 Jaber H, Lohman E, Daher N, et al. Neuromuscular control of ankle and hip during performance of the star excursion balance test in subjects with and without chronic ankle instability. PLoS One 2018;13:e0201479.

81 Batson G. Validating a dance-specific screening test for balance: preliminary results from multisite testing. Med Probl Perform Art 2010;25:110-5

82 Ko J, Rosen AB, Brown CN. Comparison between single and combined clinical postural stability tests in individuals with and without chronic ankle instability. Clin J Sport Med 2017;27:394-9.

83 Pozzi F, Moffat M, Gutierrez G. Neuromuscular control during performance of a dynamic balance task in subjects with and without ankle instability. Int J Sports Phys Ther 2015;10:520-9.

84 Thorpe JL, Ebersole KT. Unilateral balance performance in female collegiate soccer athletes. J Strength Cond Res 2008;22:1429-33.

85 Nakagawa L, Hoffman M, Static Pin. Performance in static, dynamic, and clinical tests of postural control in individuals with recurrent ankle Sprains. J Sport Rehabil 2004;13:255-68.

86 Forkin DM, Koczur C, Battle R, et al. Evaluation of kinesthetic deficits indicative of balance control in gymnasts with unilateral chronic ankle sprains. J Orthop Sports Phys Ther 1996;23:245-50.

87 Jerosch J, Bischof M. Proprioceptive capabilities of the ankle in stable and unstable joints. Sports Exerc Inj 1996;2:167-71.

$88 \mathrm{Kim}$ C-Y, Choi J-D. Comparison between ankle proprioception measurements and postural sway test for evaluating ankle instability in subjects with functional ankle instability. J Back Musculoskelet Rehabil 2016;29:97-107.

89 Buchanan AS, Docherty CL, Schrader J. Functional performance testing in participants with functional ankle instability and in a healthy control group. J Athl Train 2008;43:342-6.

90 Caffrey E, Docherty CL, Schrader J, et al. The ability of 4 singlelimb hopping tests to detect functional performance deficits in individuals with functional ankle instability. $J$ Orthop Sports Phys Ther 2009;39:799-806. 
91 Groters S, Groen BE, van Cingel R, et al. Double-leg stance and dynamic balance in individuals with functional ankle instability. Gait Posture 2013;38:968-73.

92 Fournier Belley A, Bouffard J, Brochu K, et al. Development and reliability of a measure evaluating dynamic proprioception during walking with a robotized ankle-foot orthosis, and its relation to dynamic postural control. Gait Posture 2016;49:213-8.

93 Steinberg N, Adams R, Ayalon M, et al. Recent ankle injury, sport participation level, and tests of proprioception. J Sport Rehabil 2019:824-30.

94 Docherty CL, Arnold BL, Gansneder BM, et al. Functionalperformance deficits in volunteers with functional ankle instability. J Athl Train 2005;40:30-4.

95 Hertel J, Miller SJ, Denegar CR. Intratester and intertester reliability during the Star excursion balance tests. J Sport Rehabil 2000;9:104-16.

96 Hyong IH, Kim JH. Test of intrarater and interrater reliability for the StAR excursion balance test. J Phys Ther Sci 2014;26:1139-41.

97 Kinzey SJ, Armstrong CW. The reliability of the star-excursion test in assessing dynamic balance. J Orthop Sports Phys Ther 1998;27:356-60.

98 Munro AG, Herrington LC. Between-session reliability of the star excursion balance test. Phys Ther Sport 2010;11:128-32.

99 Amacker A, Meng J, Jordan K, et al. Responsiveness of the Star excursion balance test on firm and unstable underground. Schweiz Z Für Sportmed Sporttraumatologie 2015;63:24-8.

100 Gribble PA, Kelly SE, Refshauge KM, et al. Interrater reliability of the star excursion balance test. J Athl Train 2013;48:621-6.

101 van Lieshout R, Reijneveld EAE, van den Berg SM, et al. Reproducibility of the modified StAR excursion balance test composite and specific reach direction scores. Int J Sports Phys Ther 2016;11:356-65.

102 Augustsson J, Thomeé R, Lindén C, et al. Single-leg hop testing following fatiguing exercise: reliability and biomechanical analysis. Scand J Med Sci Sports 2006;16:111-20.
103 Shumway-Cook A, Woollacott MH. Motor control: translating research into clinical practice. Wolters Kluwer Health/Lippincott Williams \& Wilkins, 2012. https://books.google.ca/books?id= PXSSSQAACAAJ

104 Basnett CR, Hanish MJ, Wheeler TJ, et al. Ankle dorsiflexion range of motion influences dynamic balance in individuals with chronic ankle instability. Int J Sports Phys Ther 2013;8:121-8.

105 Terada M, Harkey MS, Wells AM, et al. The influence of ankle dorsiflexion and self-reported patient outcomes on dynamic postural control in participants with chronic ankle instability. Gait Posture 2014;40:193-7.

106 Riemann BL, Lephart SM. The sensorimotor system, part II: the role of proprioception in motor control and functional joint stability. J Athl Train 2002;37:80.

107 Bouyer L, Grey MJ, Nielsen JB. Adaptive plasticity of gait. In: Routledge Handbook of motor control and motor learning. Routledge, 2012: 213-30.

108 Grey MJ, Nielsen JB, Mazzaro N, et al. Positive force feedback in human walking. J Physiol 2007;581:99-105.

109 Grey MJ, Mazzaro N, Nielsen JB, et al. Ankle extensor proprioceptors contribute to the enhancement of the soleus EMG during the stance phase of human walking. Can J Physiol Pharmacol 2004:82:610-6.

110 Mokkink LB, Terwee CB, Patrick DL, et al. The COSMIN study reached international consensus on taxonomy, terminology, and definitions of measurement properties for health-related patientreported outcomes. J Clin Epidemiol 2010;63:737-45.

111 Roy J-S, MacDermid JC, Woodhouse LJ. Measuring shoulder function: a systematic review of four questionnaires. Arthritis Rheum 2009;61:623-32.

112 Portney LG, Watkins MP. Foundations of clinical research: applications to practice. Pearson/Prentice Hall, 2015. https:// books.google.ca/books?id=jNyECwAAQBAJ

113 Carter R, Lubinsky J. Rehabilitation Research- E-Book: principles and applications. Elsevier Health Sciences, 2015. https://books. google.ca/books?id=7osNCgAAQBAJ 